\title{
BIOCHEMICAL PARAMETERS OF LIPID METABOLISM IN ANIMALS AFFECTED BY HEAVY METAL SALTS AND TREATED WITH CARNITINE CHLORIDE AND SODIUM ALGINATE
}

\author{
I. R. Bekus, M. V. Kyryliv, I. B. Ivanusa, O. B. Furka, I. Y. Krynytska, M. I. Marushchak \\ I. HORBACHEVSKY TERNOPIL STATE MEDICAL UNIVERSITY, TERNOPIL, UKRAINE
}

Background. Lipid metabolism disorders in the organism affected by environmental pollutants, including poisoning with cadmium and lead salts are of topical matter nowadays.

Objective. The study was aimed to examine biochemical features of lipid metabolism in rats subjected to toxic damage by lead and cadmium salts and treated with carnitine chloride and Algigel.

Methods. Experiments were carried out on white mature outbred male rats weighing 180-200 g. To cause the toxic damage the animals were administered with aqueous solution of cadmium chloride and lead acetate daily for the period of 30 days using intra-gastric lavage. The indices of lipid metabolism were detected by biochemical methods.

Results. In animals treated with cadmium chloride and lead acetate the following changes were observed: HDL-cholesterol concentrations significantly decreased, resulting in $87 \%$ of the levels in the intact animals on the third day, $84 \%$ on the fifth and $80 \%$ on the seventh day. Conversely, concentrations of HDL-cholesterol and VLDLcholesterol significantly increased during the experiment. Respectively, the ratios for HDL-cholesterol are 240\%, $352 \%$, and 388\%; and for VLDL-cholesterol 108\%, 116\%, and 132\%.

Conclusions. Lipids profile of the rats displayed changes in the levels of cholesterol, triglycerides and lipoproteins of low, high and very low density.

KEY WORDS: blood lipid profile, heavy metal toxicity.

\section{Introduction}

The lipid metabolism disorders in the organism affected by environmental pollutants including poisoning with cadmium and lead salts were extensively studied. Salts of these metals are assigned Class II of toxicity in the European Union's classification system, which is regulated by Directive 67/548/EEC. They have a large migration ability (in the soil to plant, and animal to person systems), and also high cumulativeness $[4,14]$. This creates a threat of their increased uptake if an organism is exposed to several contaminated sources at once: inhaling the air (car exhaust), soil particles along the roadways, industrial dust, and ingesting fertilizer residue with vegetables and produce $[8,9]$. Due to their association with industrial waste, these compounds often occur in combination. However, although there is a

Corresponding author: Iryna Bekus, Department of Medical Biochemistry, I. Horbachevsky Ternopil State Medical University, 1 Maidan Voli, Ternopil, Ukraine, 46001

Phone number: +38035252433

E-mail: bekus@tdmu.edu.ua large amount of the literature describing mechanisms of action of either lead or cadmium salts on the body, the number of studies of the combined effect of these two toxins is limited $[16,17]$.

This study demonstrates that in rats lipid metabolism disorders caused by the combined toxic effect of Cadmium (Cd) and Plumbum (Pb) ions were effectively corrected after carnitine chloride and sodium alginate administration. This conclusion is proved by changes in the concentrations of lipid metabolism biomarkers in blood plasma.

\section{Material and Methods}

Experiments were carried out on white mature outbred male rats weighing 180-200 g, which were kept on a standard diet and housed in the animal facility of Ternopil State Medical University. The animal maintenance, treatment and euthanasia were conducted in accordance with the internal safety and ethical regulations, as well as European convention for the protec- 
tion of vertebrate animals used for experimental and other scientific purposes [15], and Applied recommendations for the maintenance and work with laboratory animals [10].

To cause the toxic damage, animals were administered with aqueous solution of cadmium chloride, dose $3.3 \mathrm{mg} / \mathrm{kg}\left(0.05 \mathrm{LD}_{50}\right)$, and lead acetate, dose $11 \mathrm{mg} / \mathrm{kg}\left(0.05 \mathrm{LD}_{50}\right)^{50}$, daily for the period of 30 days using intra-gastric lavage [2].

The treatment used for toxic damage correction consisted of $2 \%$ solution of carnitine, dose $50 \mathrm{mg} / \mathrm{kg}$, and enterosorbent (chelator) Algigel, dose $400 \mathrm{mg} / \mathrm{kg}[5,12]$. Both of these substances were administered daily using intragastric lavage.

All experimental animals were divided into the following groups: Group 1, intact rats; Group 2 (control), animals treated with cadmium chloride and lead acetate; Group 3, animals treated with cadmium chloride, lead acetate as well as carnitine and Algigel enterosorbent.

After finishing the heavy metals and corrective agents administration, we tested the lipid metabolism rates on the $3^{\text {rd }}, 5^{\text {th }}$ and $7^{\text {th }}$ days. To determine lipid metabolism the following methods were used: triacylglycerols (TG) were extracted from blood serum using isopropanol with simultaneous removal of phospholipids mix from the reaction by precipitation with aluminum oxide [3]; the presence of cholesterol was determined using a colour reaction whereby in the presence of acetate anhydride and a mixture of acetic and sulphuric acid a green compound was formed [1]. Levels of cholesterol were evaluated by the intensity of the colour using colorimetry. Free cholesterol was detected using digitonin precipitation [3]. Cholesterol-digitonin complex was subsequently dissolved in chloroform, evaluated by Liebermann-Burchard test. The level of highdensity lipoprotein (HDL) cholesterol was determined in soluble fraction after low density (LDL) and very low-density (VLDL) cholesterols in blood plasma were precipitated using heparin in the presence of manganese ions [4]. Levels of LDL and VLDL cholesterols were evaluated by mathematical models.

The results of the study were analyzed by the Department of Statistical Research of Ternopil State Medical University using STATISTICA software (StatSoft). Arithmetic mean of the sample (m), its variance and mean squared error (MSE) were calculated for all biochemical indices. Significance of the difference between independent quantitative values was determined using Student's t-test.

\section{Results and Discussion}

Cadmium and lead belong to a group of heavy metals; their ions have the ability to accumulate in the body. Since in this study these substances were administered for 30 consecutive days in subthreshold doses, we looked for general toxic effect in addition to the parameters of lipid metabolism. Thus, for the duration of the experiment, we observed the influence of cadmium chloride and lead acetate on the overall condition of the animals, change in body mass, peripheral blood composition and certain other hematological parameters [7, 8, 11, 13].

The early symptoms of poisoning with heavy metal are: rejection of food by the animal, general depression, and weight loss. Our observations indicate that on the $5^{\text {th }}$ day of the experiment, the control group of animals sometimes refused their food or ate smaller quantities compared to the intact animals. We also observed lethargy, reduced movements, and changes in fur cover. To prove these observations, we measured body mass of the intact and control animals, which allowed us to determine its changes.

We determined the levels of total cholesterol, triacylglycerols (TG), HDL, LDL and VLDL cholesterol in plasma of the experimental and control animals [6]. The data presented in Table 1 proves that in plasma of the animals injected with heavy metals, the concentrations of TG significantly increased compared to intact animals, for instance on the third day the it was $186 \%$, on the fifth $-179 \%$, and on the seventh $166 \%$ of the levels of the intact animals.

We consider that the increase of triacylglycerol levels in response to prolonged cadmium chloride and lead acetate intoxication occurs according to a specific mechanism. The intoxication by salts of lead and cadmium causes disruption of energy processes at the mitochondria. This evidences the activation of tissue lipases and mobilizing of fatty acids from fat depots, which are rapidly delivered to the liver synthesizing the surplus amounts of triacylglycerols.

Cholesterol is an important indicator allowing lipid metabolism evaluation. Under physiological conditions, the levels of cholesterol in the body are in a state of equilibrium between HDL and LDL cholesterols: the amount of cholesterol incoming with food and synthesized de novo corresponds to what is excreted as bile 


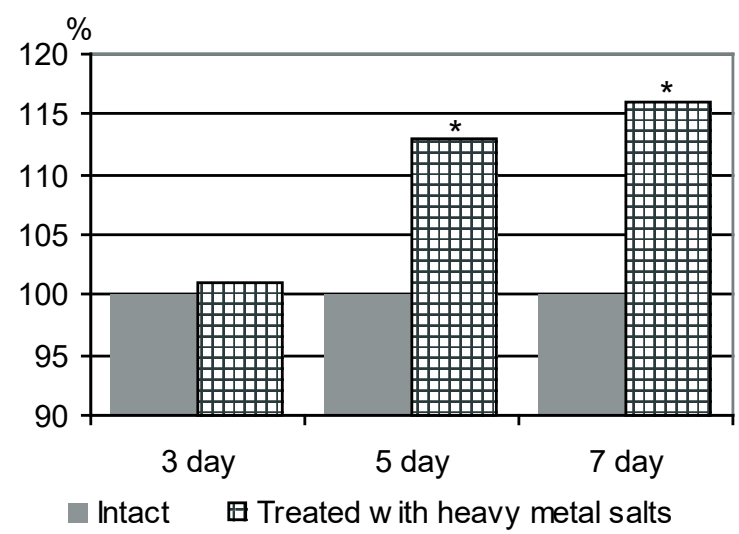

Figure 1. Total cholesterol content in blood plasma of the animals.

Notes: * - significant difference if compared to the control animals.

acids and free cholesterol. In this study, the concentration of total cholesterol in blood of the intact animals was $2.18 \pm 0.09 \mathrm{mmol} / \mathrm{L}$ (Table 1), but it was different in the group of the animals that received heavy metal salts. The maximal differences between the two groups were recorded on the seventh day after the beginning of toxicant administration, when cholesterol concentration increased by $16 \%$ in the treated animals compared to the intact ones.

Cholesterol is present in blood as its free form and its esters of fatty acids. Each of these forms has specific physiological functions and diagnostic value for understanding of lipid metabolism disorders. Free cholesterol is exchanged between tissues, so its concentration in serum reflects the total content of cholesterol in the body. The results of this study prove that there are significant differences in the rates of different form of cholesterol between the intact and control groups.

Thus, toxic action of heavy metal ions disrupts esterification of cholesterol decreasing concentrations of its esters in blood serum.

Lipids are transported in blood as complex supramolecular complexes, lipoproteins. Therefore, in this study we determined concentrations of different lipoprotein classes. In the animals treated with cadmium chloride and lead acetate the following changes were observed: HDL-cholesterol concentrations significantly decreased, resulting $87 \%$ of the levels in the intact animals on the third day, $84 \%$ on the fifth day and $80 \%$ on the seventh day. Conversely, the concentrations of HDL-cholesterol and VLDL-cholesterol significantly increased during the experiment. Respectively, the rates for HDL-cholesterol were $240 \%$, 352\%, and $388 \%$; and for VLDL-cholesterol - 108\%, $116 \%$, and $132 \%$ (Table 1 ).

Treatment of exogenous intoxication involves the use of antioxidants, metabolic factors,

Table 1. Concentrations of total cholesterol, triacylglycerols, HDL, LDL and VLDL cholesterol in rats' blood serum during 30-day administration of cadmium chloride and lead acetate $(n=6)$

\begin{tabular}{|c|c|c|c|}
\hline \multirow{2}{*}{$\begin{array}{c}\text { Intact animals, } \\
\text { group } 1\end{array}$} & \multicolumn{3}{|c|}{ Animals treated with cadmium chloride and lead acetate, group 2} \\
\hline & $3^{\text {rd }}$ day & $5^{\text {th }}$ day & $7^{\text {th }}$ day \\
\hline $0.86 \pm 0.06$ & $\begin{array}{c}1.60 \pm 0.09 \\
p_{1}<0.01\end{array}$ & $\begin{array}{l}1.54 \pm 0.08 \\
p_{1}<0.01\end{array}$ & $\begin{array}{c}1.43 \pm 0.08 \\
p_{1}>0.05\end{array}$ \\
\hline \multicolumn{4}{|c|}{ Total cholesterol, blood plasma, $\mathrm{mmol} / \mathrm{L}$} \\
\hline $2.18 \pm 0.09$ & $\begin{array}{c}2.21 \pm 0.17 \\
p_{1}>0.05\end{array}$ & $\begin{array}{c}2.46 \pm 0.18 \\
p_{1}>0.05\end{array}$ & $\begin{array}{c}2.54 \pm 0.18 \\
p_{1}>0.05\end{array}$ \\
\hline \multicolumn{4}{|c|}{ Esterified cholesterol, blood plasma, $\mathrm{mmol} / \mathrm{L}$} \\
\hline $1.52 \pm 0.07$ & $\begin{array}{c}0.91 \pm 0.07 \\
\mathrm{p}_{1}<0.05\end{array}$ & $\begin{array}{c}0.96 \pm 0.09 \\
\mathrm{p}_{1}<0.05\end{array}$ & $\begin{array}{c}1.27 \pm 0.08 \\
\mathrm{p}_{1}<0.05\end{array}$ \\
\hline \multicolumn{4}{|c|}{ Free cholesterol, blood plasma, mmol/L } \\
\hline $0.66 \pm 0.04$ & $\begin{array}{c}1.30 \pm 0.11 \\
\mathrm{p}_{1}<0.05\end{array}$ & $\begin{array}{c}1.50 \pm 0.11 \\
\mathrm{p}_{1}<0.05\end{array}$ & $\begin{array}{c}1.27 \pm 0.08 \\
\mathrm{p}_{1}<0.05\end{array}$ \\
\hline \multicolumn{4}{|c|}{ HDL-cholesterol, blood plasma, $\mathrm{mmol} / \mathrm{L}$} \\
\hline $1.54 \pm 0.02$ & $\begin{array}{r}1.34 \pm 0.11 \\
p_{1}>0.05\end{array}$ & $\begin{array}{l}1.29 \pm 0.04 \\
p_{1}<0.01\end{array}$ & $\begin{array}{l}1.24 \pm 0.04 \\
\mathrm{p}_{1}<0.001\end{array}$ \\
\hline \multicolumn{4}{|c|}{ LDL-cholesterol, blood plasma, $\mathrm{mmol} / \mathrm{L}$} \\
\hline $0.25 \pm 0.07$ & $\begin{array}{c}0.60 \pm 0,03 \\
p_{1}<0.01 \\
\end{array}$ & $\begin{array}{c}0.88 \pm 0.13 \\
\mathrm{p}_{1}<0.01 \\
\end{array}$ & $\begin{array}{c}0.97 \pm 0.10 \\
\mathrm{p}_{1}<0.01\end{array}$ \\
\hline \multicolumn{4}{|c|}{ VLDL-cholesterol, blood plasma, $\mathrm{mmol} / \mathrm{L}$} \\
\hline $0.39 \pm 0.01$ & $\begin{array}{c}0.27 \pm 0.03 \\
\mathrm{p}_{1}<0.02\end{array}$ & $\begin{array}{c}0.29 \pm 0.01 \\
\mathrm{p}_{1}<0.001\end{array}$ & $\begin{array}{c}0.33 \pm 0.04 \\
p_{1}>0.05\end{array}$ \\
\hline
\end{tabular}

Notes: $p_{1}-$ significant difference if compared to the control animals. 
cell membrane protectors and also reducing systemic concentrations of toxic components in the body. The use of so-called efferent therapies, including enterosorbtion is one of the approaches to removing foreign substances and metabolic products.

In this study, we used the combination of carnitine and enterosorbent sodium alginate. The changes of total cholesterol in blood plasma of the experimental animals were as follows. During the whole experiment we observed significant and linear decrease of cholesterol contents in the experimental animals compared to the control group. On the third day cholesterol levels were by $75 \%$ lower in experimental group, on the fifth - by $62 \%$, and on the seventh - by $56 \%$, which was lower than in the intact animals (Table 1). This decrease was in the free cholesterol, while the concentration of esterified forms significantly increased for the period of the experiment.

In this study, we evidenced the positive effect of combined use of carnitine and sodium on the concentrations of HDL, LDL and VLDL cholesterol. The combined effect of toxicants caused a marked reduction in the concentration of HDL cholesterol at all stages of the experiment compared to the intact animals (Figure 2).

Subsequent treatment with carnitine and Algigel caused a significant increase in these rates. Thus, on the $3^{\text {rd }}$ day it increased by $12 \%$; on the $5^{\text {th }}$ by $22 \%$; and on the $7^{\text {th }}$ by $26 \%$ compared to the control animals. These rates, however, were significantly different from the corresponding rates in the intact group.

When treated with the corrective factors, carnitine and Algigel, the animals demonstrated significant decrease of LDLC concentration. In particular, on the $3^{\text {rd }}$ day this rate decreased in 3.6 times in comparison with the control animals. On the $5^{\text {th }}$ day the concentration decreased more and was in 5.8 times lower than in the control animals, and on the $7^{\text {th }}$ day it was in 8 times lower.

In the experimental group, the concentration of VLDL cholesterol on the $3^{\text {rd }}$ day increased by $79 \%$ compared to the animals of the control group, and on the $5^{\text {th }}$ and $7^{\text {th }}$ days by $50 \%$ and $36 \%$ respectively.

\section{Conclusions}

This study proved that carnitine in combination with sodium alginate had a clear positive
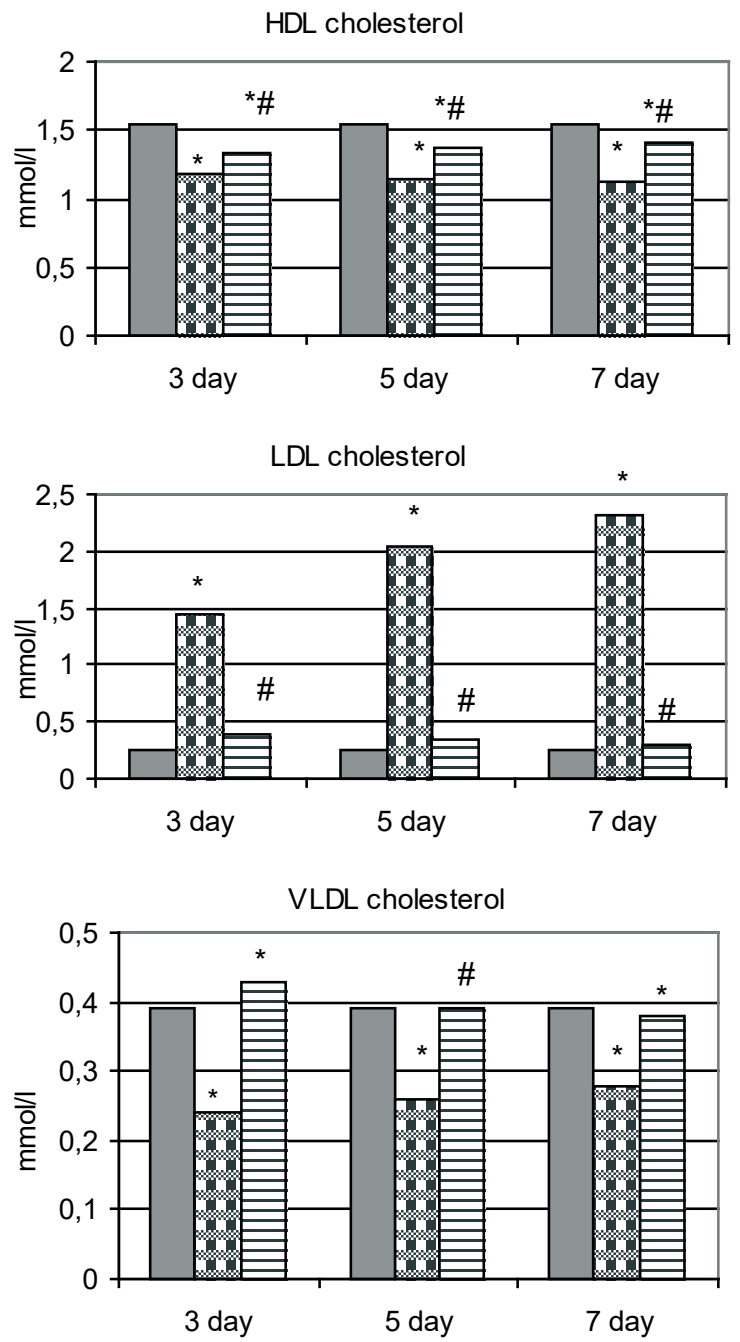

$\square$ Intact

Treated $w$ ith heavy metal salts

曰 Treated w ith heavy metal salts, plus carnitine and Algigel

Figure 2. Changes in the concentrations of HDL, LDL and VLDL cholesterol in blood plasma of the animals.

Notes: * - significant difference if compared to the control animals;

\# - significant difference if compared to the affected animals.

effect on some parameters of lipid metabolism in blood plasma of rats. The proposed means of correcting biochemical changes caused by poisoning with lead and cadmium salts in subthreshold doses demonstrated the need for further studies to develop possible use in clinical settings for correction of lipid metabolism and reducing toxic effects of xenobiotics. 


\section{References}

1. Harbarets BO, Wysocki IJ, Kachanova A. Workshop on biological chemistry. Sumy 1997; 28.

2. Gerasimenko TI, Domnin SG, Roslyi OF, Fedoruk AA. The evaluation of combined effects of leadcopper and lead-zinc binary mixtures. Med Tr Prom Ekol 2000; 8: 36-39.

3. Horyachkovskyy A. Clinical biochemistry in the laboratory diagnostics. Odessa: Ecology 2005: 607.

4. Demkiv I, Klisch I, Bekus I, Krynytska I Condition of antioxidant system with acute intoxication by ethyl alcohol against a background of protracted intoxication by salts of lead and cadmium. Second international conference of students and graduate "Youth and progress of biology", March 21-24. 2006: Theses. Lviv 2006; 46-47.

5. Dmytrukha NM. Assessment of calcium alginate influence on nonspecific resistance of white rat organism with lead intoxication. Modern problems of toxicology 2004; 4: 15-17.

6. Kamyshnikov VS. Handbook of clinical and biochemical studies, and laboratory diagnosis. Minsk: Belarus 2000; 1-2. (in Russian)

7. Melnyk MK. Exposure to ionizing radiation and lead for neuroendocrine system performance in rats and their correction: thesis abstract on competition sciences degree candidate. biol. sciences specials. 03.00.01. "Biological Chemistry". Kyiv 2003: 15.

8. Mikhaleva LM. Human pathology by cadmium dependent. Archives of Pathology 1988; 50 (9): 81-85.

9. Mikhaleva LM. Pathological anatomy experimental intoxication caused by cadmium chloride: ab- stract of the thesis for the candidate scientific degree in medical sciences: 14.00.15. Moscow 1990; 31.

10. Kozhemyakin YM, Khromov OS, Filonenko MA, Sayfetdinova GA. Scientific-practical advice on keeping laboratory animals and work with them. K.: Avicenna 2002; 156.

11. Rice RH, Gulyaeva LF. Biological effects of toxic compounds: lectures. Novosibirsk State. Univ. Novosibrsk 2003; 208.

12. Sidoryak NG, Volgin DV. Effect of L-carnitine on lipid peroxidation and lipid composition of blood serum at hemic hypoxia. Ukr. biochem. mag 1996; 68 (5): 54-58.

13. Yanchuk VV, Vlasyk LI. Features combined effect of sodium nitrate and lead acetate in subacute experiment on rats of different ages. Bukovina's Medical Journal 2003; 7 (4): 163-167.

14. Brind A, Hurlstone A, Edrisinghe D. The role of polymorphisms of glutathione S-transferases GSTM ${ }_{1}, M_{3}, P_{1}, T_{1}$, and $A_{1}$ in susceptibility to alcoholic liver disease. Alcohol 2004; 39 (6): 478-483.

15. European convention for the protection of vertebrate animals used for experimental and other scientific purposes. Council of Europe. Strasbourg 1986; 123: 52.

16. Rana S, Verma S. Protective effects of GSH, vitamin $E$ and selenium on lipid peroxidation in cadmium fed rats. Boil. Trace Element Res 1998; 2: 161-168.

17. Sies H. Oxidative stress: oxidants and antioxidants. Exp. Physiol 1997; 82 (2): 291-295. 